\title{
The Role of Information and Communication Sharing Pathway in Improving Peri-Urban Dairy System of Bamako, Mali
}

\author{
Sidibe M'baye Thiam ${ }^{1}$, Joseph Wafula Matofari' \\ ${ }^{1}$ Department of Crops, Horticulture and Soils, Egerton University, Nakuru, Kenya \\ ${ }^{2}$ Department of Dairy, Food Science and Technology, Egerton University, Nakuru, Kenya \\ Email address: \\ sibe_t@yahoo.com (S. M. Thiam)
}

\section{To cite this article:}

Sidibe M'baye Thiam, Joseph Wafula Matofari. The Role of Information and Communication Sharing Pathway in Improving Peri-Urban Dairy System of Bamako, Mali. American Journal of Science, Engineering and Technology. Vol. 3, No. 1, 2018, pp. 21-28. doi: $10.11648 /$ j.ajset.20180301.13

Received: November 10, 2017; Accepted: November 25, 2017; Published: March 6, 2018

\begin{abstract}
Information Communication Technology (ICT) has been used as one of the intervention strategies in the reduction of post-harvest losses along the agricultural value chains in the developing countries. ICT has been used in Malian agriculture in general as an intervention strategy, but not specifically in the dairy sector. In recent years there has been an improvement in the dairy sector due to the peri-urban dairy farming, which has resulted into intensification of the milk production because of improved breeds and the easy access to feed. Despite the increase in the volume of milk production in Mali that has been estimated to be about 2 billion liters per year, only $45 \%$ of this production is being utilized. The aim of this study was to determine the role of ICT in reducing these losses in peri-urban of Bamako. Data was obtained through semi-structured questionnaires and interviews. Multiple-stage sampling procedure was used to select the respondents $(\mathrm{n}=171)$. The most common information sharing pathway used by the peri-urban sub-value chain actors was the mobile phone with $93 \%$ at the farm level, $89 \%$ at the transportation level and $71 \%$ at the cooperative level. The most sought type of information by peri-urban dairy farmers at the cooperatives was on feeds at $42 \%$, animal health at $14 \%$ and cooperative issues at $13 \%$. Information sharing through mobile phone was the most type of communication pathway used and therefore can be used an ICT intervention that can contribute towards reducing milk post-harvest losses along the value chain.
\end{abstract}

Keywords: ICT, Post-Harvest Losses, Peri-Urban Dairy System, Value Chain

\section{Introduction}

Livestock production is important in Mali's agriculture sector and contributes approximately $30 \%$ of GDP [1]. Economically livestock sector is in the third place after cotton and gold with a contribution to exportation estimated to $\$ 8$ million per year [2]. At least, $90 \%$ of farmers in Mali practice livestock keeping for milk production, some of which is sold to bring cash income to the family [3]. Livestock production has increased, and provides adequate products for domestic consumption, and a marketable surplus commercial production system for milk and meat [4]. Malian dairy sub-sector is changing rapidly because of strong market for dairy products and can be offered to producers by encouraging them to invest in new technologies; in response, market-oriented cooperatives are growing and private-sector service providers are stepping into the domain [5].

Although statistics differ from one source to another, Malian milk production is estimated to be about 2 billion liters per year and only $45 \%$ of this production is used [3]. Nevertheless, Mali is still importing 10 to 15 billion FCFA (200 million to 300 million of US Dollars) worth of dairy products up through 2010 and milk consumption was below Mali's target of 40 liters/capital. Peri-urban milk production has become more intensive than rural milk production because of improved breeds and easy access to animal feeds. This has improved milk production to 20 liters per day [1].

The use of Information Communication Technology (ICT) for instance radios, television, mobile phones and internet provides vital information to dairy actors on available opportunities to access support services that may increase production and profitability of dairy products and reduce 
milk losses [6]. In the last decade ICT tools have revolutionized our lives and have made it easier for us to overcome long distance and time barrier in agricultural information dissemination. In order to look for new market opportunities, farmers need to be innovative, to become more efficient producers and effective entrepreneurs. Farmers need information and new technologies for effective communication and quick access to markets. The access to the right market information for potential consumers would assist farmers to make informed decisions on market information [7].

ICT use in agricultural sectors has been embraced not only in Africa and but also worldwide because of its benefits to improve productivity, increase market and reduce postharvest losses [8]. Countries like Kenya, India and Ghana have managed to introduce ICT projects that have promoted agriculture in the rural communities. In Kenya, village farmers have improved market efficiency through the use of ICTs by easily accessing information using ICT tools such as radios, cellphones, telephones and the internet. Thus the introduction of ICTs reduced transaction costs and improved the communication between buyers and sellers [9]. In Namibia ICT has been used as a tool to trace livestock through the Namibian Livestock Identification and Traceability System (NamLITS) project [10].

There are many successful examples of ICT intervention strategy in the agricultural sector. One of such intervention is the mFarmer Initiative in support of projects in Sub-Saharan Africa, launched in 2011 in partnership with the Bill and Melinda Gates Foundation and USAID. The purpose of mFarmer Initiative is to stimulate the development of mobile phone-enabled agriculture information and advisory services that are commercially sustainable and build services that impact farmers' income and productivity. Another example is the Esoko, which is well established mobile technology service in agriculture that has been operating in Ghana since 2005. The Esoko Ghana Commodity Index (EGCI) is a rural communication platform that publishes a cash market price index composed of data on physical commodities. The index is published weekly and tracks wholesale and retail prices and aims to improve farmers' incomes by building healthy markets. Also there is Icow ICT services in Kenya. Icow is an SMS app developed to enable dairy farmers access unbiased information concerning the cows' gestation period, vet info, record keeping and the world's first cow calendar.

The Malian milk value chains have been facing many challenges since the privatization of the national firm (MaliLait) due to structural adjustment program in the 1990s. Today the main constraint in Mali's dairy value chain is lack of flow of information on extension services, market availability, milk quality and other important information among dairy stakeholders. This has consequently resulted into very high milk losses due to poor milk handling practices, animal diseases and lack of market for the harvested milk. The use of ICT between dairy actors can used to bridge this gap so as to reduce transaction costs and increase incomes and lower consumer prices [7]. Therefore, the aim of this study was to assess the use of ICT in the periurban dairy value chains of Bamako in Mali and recommending the best ICT strategy that can be used to reduce milk post-harvest losses.

Statement of the Problem

The dairy sub-sector in Mali has the potential to play a major role in the general development goal of Mali. The subsector is growing rapidly, particularly in the peri-urban areas because of increased demand for dairy products in urban areas. The losses of milk along the milk value chains is estimated to be $65 \%$ of the national production, because the main players (farmers, informal traders, distributors and retailers) are not having access to the accurate information about milk production and processing practices. In spite of the increase in volume of production that is estimated to be 2 billion litres national wide, dairy farmers still experience market information challenges resulting into low profit due to milk loss through spoilage and spillage. The causes of lack of access to correct information on dairy production include undefined sources of information, type of information, and type of medium to be used to pass the information. There are many ICT pathways but farmers' transporters and cooperatives may not be aware of which ICT pathway is more convenient, especially in smallholder farmers. Therefore, this study aimed at assessing the role of ICT in reducing milk losses in peri-urban Bamako.

\section{Methodology}

A random multi-stage sampling technique was used to select actors (farmers, milk transporters and cooperatives) in peri-urban Bamako. Primary and secondary data were collected, the first stage was based on complete the literature review from the data obtained from the DNPIA (Direction National des Productions and des Industries animals). The second stage was the data collection by using semi-structured questionnaires and interviews of the dairy actors in the dairy sub-value chain. The simple random sampling technique was used to identify actors in the dairy value chains within Bamako and peri-urban areas. The survey was to interview a range of different actors including the dairy farmers, the dairy farmers associations, and the cooperatives. The questionnaire consisted of information on how the different actors receive information relative to the dairy sector (for example, radio, television, SMS and cell phones, Internet), the type of information sought in relation to dairy farming and the sources of this information.

\section{Results}

\subsection{Sources and Type of Information Used by the Peri-Urban Dairy Farmers in Bamako}

Type of information that peri-urban dairy farmers are looking for at the cooperative level is shown in Table 1. Among all the types of the information shared by the cooperatives, information on feed was the most sought after 
at $42.07 \%$ whereas the least sought after information was milk quality at $1.98 \%$. All the cooperatives have at least one extension worker attached to them from the local Nongovernmental organizations (NGOs) and government.

Table 1. Type of information shared by cooperatives.

\begin{tabular}{ll}
\hline Type of information shared & Frequency $(\%)$ \\
\hline Feed & 42.07 \\
Breed & 6.93 \\
Land accessibility & 2.97 \\
Sanitation & 11.39 \\
Animal health & 14.85 \\
Cooperatives problems & 13.37 \\
Milk quality & 1.98 \\
Milk price & 3.96 \\
Finance & 2.48 \\
\hline
\end{tabular}

Information sharing pathways used by cooperatives are shown in Table 2. Mobile phone was the most used information sharing pathway between cooperatives and farmers at $71.43 \%$. Extension workers and village chief were the least information sharing pathways used by the farmers to seek information from the cooperatives at $0.89 \%$ each.

Table 2. Information pathways used by cooperatives.

\begin{tabular}{ll}
\hline Information pathways & Frequency (\%) \\
\hline Farmer to farmer & 1.79 \\
Cooperatives meetings & 11.61 \\
Extension workers & 0.89 \\
Letters & 9.82 \\
Village chief & 0.89 \\
Mobile phone & 71.43 \\
Radio & 3.57 \\
\hline
\end{tabular}

Sources of information used by the peri-urban dairy farmers in Bamako are shown in Figure 1. The cooperative was the highest source of information used by the farmers at $80.2 \%$ whereas the middlemen were the least source of information used by dairy farmers at $0.5 \%$. Other sources of information used by farmers were neighbours $4.4 \%$, farmer to farmer $13.7 \%$ and informal traders at $1.1 \%$.

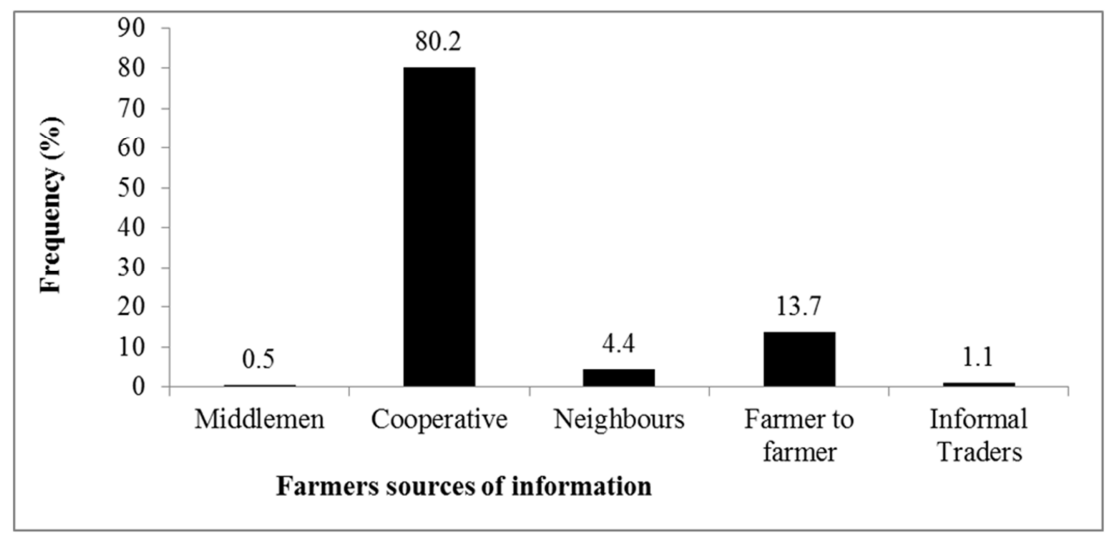

Figure 1. Sources of information used by the peri-urban dairy farmers in Bamako, Mali.

Type of information sought by the peri-urban dairy farmers in Bamako is shown in Figure 2. Milk price was the highest sought after type of information at $59.3 \%$ whereas information on animal health was the least sought after at
$1.1 \%$. Other types of information sought by the farmers were milk quality at $15.9 \%$, milk market availability at $3.8 \%$, animal feed at $5.5 \%$ and any other available information at $14.3 \%$.



Figure 2. Type of information sought by the peri-urban dairy farmers in Bamako, Mali.

The different communication channels used for seeking information by peri-urban dairy farmers from different sources and types are shown in Table 3. Among the different communication channels used, mobile phone was the most frequent used to seek information from the cooperative, neighbours and informal traders. Mobile phone use as a 
communication channel was the highest for seeking information on animal feeding at $70 \%$ followed by milk price at $65.7 \%$ and milk quality at $62.00 \%$. Face to face was the most used channel of communication with middlemen, neighbours and seeking information from the cooperatives.

Table 3. The different communication channels used for seeking information from different sources.

\begin{tabular}{|c|c|c|c|c|c|}
\hline \multirow{2}{*}{\multicolumn{2}{|c|}{ Information }} & \multicolumn{4}{|c|}{ Channels of communication } \\
\hline & & Mobile Phone & Radio & Village Chief & Face to Face \\
\hline \multirow{5}{*}{ Source } & Middlemen & $0.00 \%$ & $0.00 \%$ & $0.00 \%$ & $100 \%(37 / 37)$ \\
\hline & Cooperative & $54.10 \%(79 / 146)$ & $0.70 \%(1 / 146)$ & $0.70 \%(1 / 146)$ & $44.5 \%(65 / 146)$ \\
\hline & Neighbours & $0.00 \%$ & $0.00 \%$ & $0.00 \%$ & $100.0 \%(8 / 8)$ \\
\hline & Farmer to Farmer & $76.00 \%(19 / 25)$ & $0.00 \%$ & $0.00 \%$ & $24.00 \%(6 / 25)$ \\
\hline & Informal Traders & $100.00 \%(2 / 2)$ & $0.00 \%$ & $0.00 \%$ & $0.00 \%$ \\
\hline \multirow{3}{*}{ Type } & Animal Feed & $70.00 \%(7 / 10)$ & $10(1 / 10)$ & $10(1 / 10)$ & $10(1 / 10)$ \\
\hline & Milk Price & $65.70 \%(71 / 108)$ & $14.81 \%(16 / 108)$ & $0.93 \%(1 / 108)$ & $18.52 \%(20 / 108)$ \\
\hline & Milk Quality & $62.00 \%(62 / 100)$ & $0.00 \%$ & $0.00 \%$ & $38.00 \%(38 / 100)$ \\
\hline
\end{tabular}

\subsection{Information Sharing Strategies Used by the Peri-Urban} Dairy Cooperatives in Bamako, Mali

Cooperative membership of peri-urban dairy farmers of Bamako is shown in Figure 3. The majority of peri-urban dairy farmers are members of dairy cooperatives at $71 \%$ whereas $29 \%$ of them are not members. Some of the farmers who are not members of the cooperatives have already applied for membership in several cooperatives but are still on waiting list to become approved members.

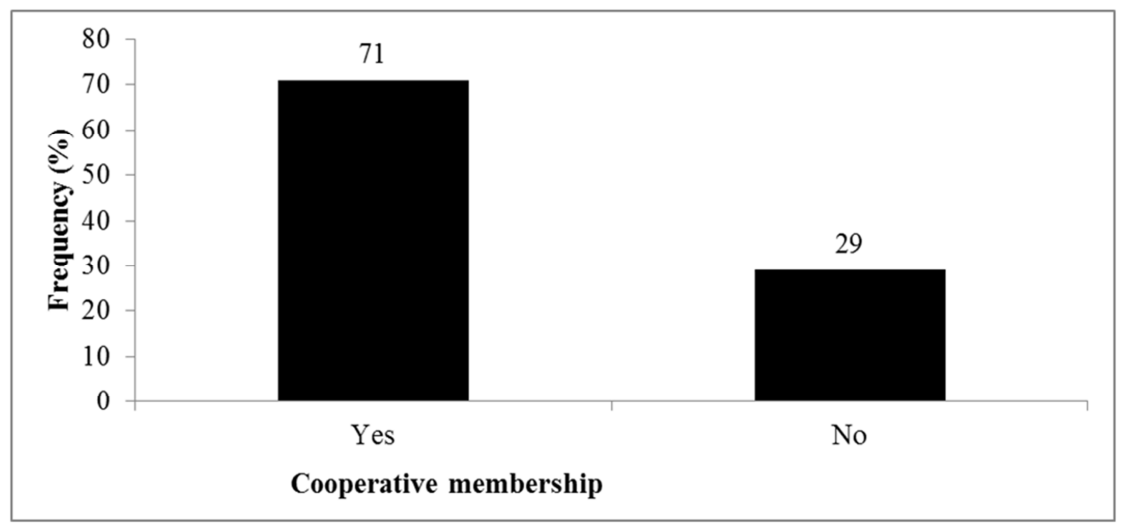

Figure 3. Cooperative membership of peri-urban dairy farmers of Bamako, Mali.

\subsection{Common Information Sharing Pathways Used in the Peri-Urban Dairy Sub-Value Chain}

Common information sharing pathways used in the periurban dairy sub-value chain are shown in Figure 4. Mobile phone use was the most the common information sharing pathway along the peri-urban dairy sub-value chain with $93.4 \%$ at the farm level, $89.2 \%$ at the transportation level and $71.43 \%$ at the cooperative level.

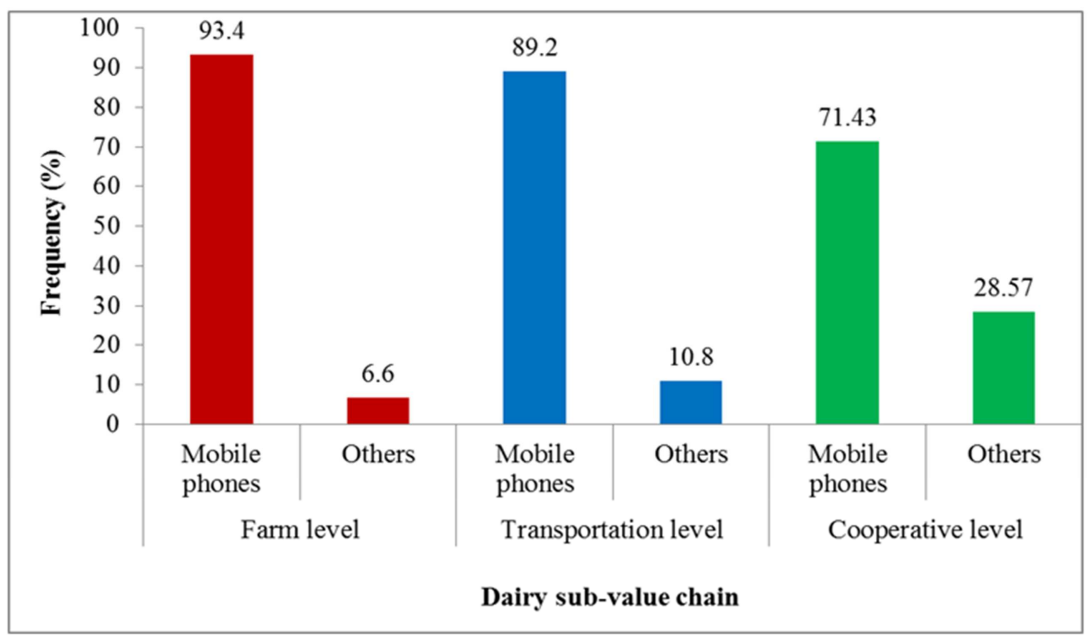

Figure 4. Common information sharing pathways used in the peri-urban dairy sub-value chain. 
Flow diagram of information sharing strategies network and diffusion in Bamako peri-urban farming system is shown in Figure 5. Among the main communication platform at all levels of the peri-urban dairy sub-value chain, mobile phone was the most commonly used. The communication network involved use of mobile phone by farmers and transporters to acquire information whereas the cooperatives were using the mobile phone as well to respond to farmers.

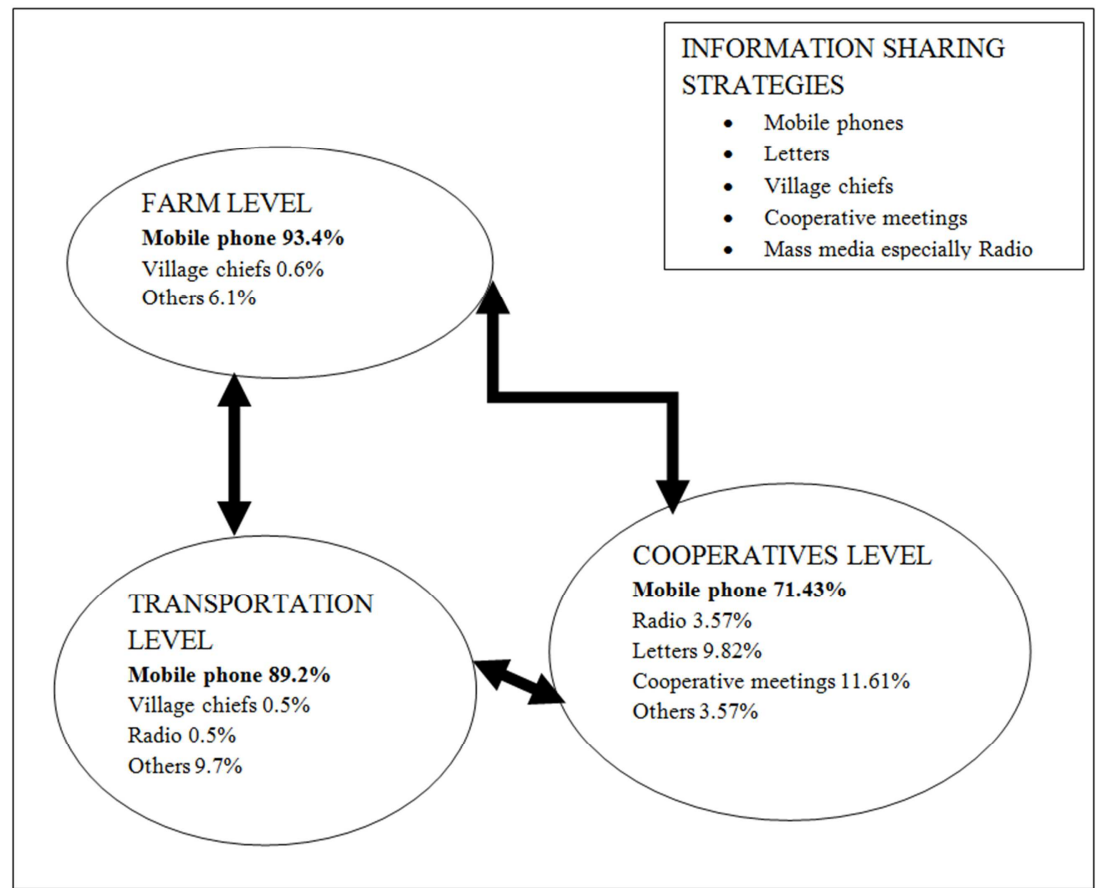

Figure 5. Flow diagram of information sharing strategies network and diffusion in Bamako peri-urban farming system.

\subsection{Recommended ICT Intervention to Reduce the Milk Losses and Increased Along the Peri-Urban Dairy Sub-Value Chain}

Recommended ICT to reduce the milk losses and increase income throughout the peri-urban dairy value chain is shown in Figure 6. The recommended ICT solution is the development and use of a mobile application that will link all dairy actors along the value chain with relevant information from the cooperative. The information will help actors to reduce milk losses and increase productivity and income throughout the value chain.

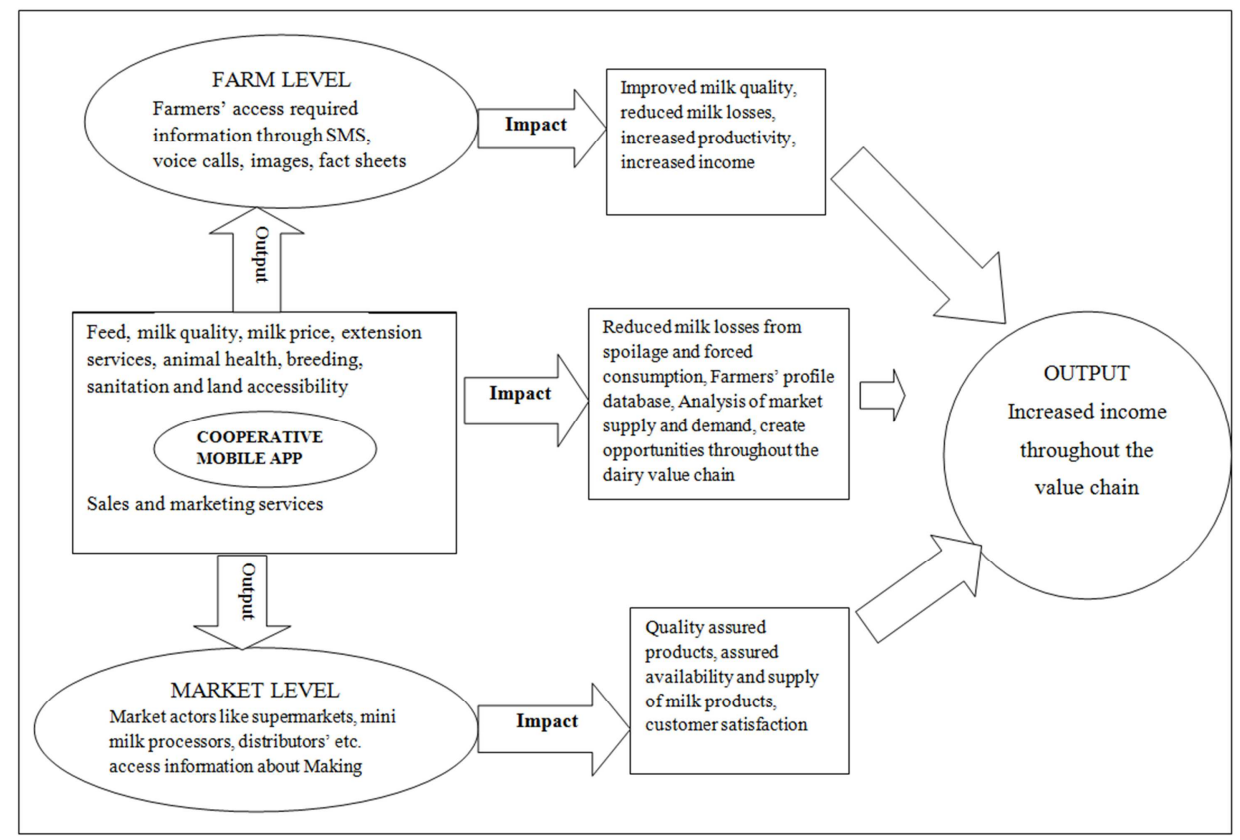

Figure 6. Recommended ICT to reduce the milk losses and increased income throughout the peri-urban dairy value chain. 


\section{Discussion}

Information on the animal feed was the highest sought at the cooperatives because during dry season feed is very expensive and cooperative members get these feed on subsidies, whereas information on milk quality was the least sought at the cooperative because farmers get training on this issue through the cooperatives NGOs periodically. The frequency of the type of information that dairy farmers are looking for at the cooperative level is shown in Table 1. Information on feed was the most sought after at $42.07 \%$ because farmers who are members of these cooperatives do get subsidies on animal feed and milk exchange for feed as a form barter trade. Peri-urban dairy farmers in Mali are faced with problems of grazing land availability thereby making the animal feeding more expensive. After feed, the second most sought after information was animal health at $14.85 \%$, problems facing the cooperatives at $13.37 \%$ and sanitation at $11.39 \%$. Whereas the least sought information was on milk quality at $1.98 \%$ because dairy farmers have been trained by the cooperatives on clean milk production practices.

Mobile phone was the most used information sharing pathway by the cooperative members to seek information from the cooperatives at $71.43 \%$ as shown in Table 2 . Extension workers and village chief were the least information sharing pathways used by the farmers to seek information from the cooperatives at $0.89 \%$ each. These cooperatives were primarily formed by dairy farmers to provide information, knowledge and extension services about dairy production, among other roles.

Peri-urban dairy farmers had different sources of information about dairy production. The most common source was the cooperatives at $80.2 \%$ as shown in Figure 1 . Type of information sought by the peri-urban dairy farmers in Bamako is shown in Figure 2. Milk price was the highest sought after type of information at 59.3\% whereas information on animal health was the least sought after at $1.1 \%$.

The study found out that majority of peri-urban dairy farmers are members of dairy cooperatives at $71 \%$ as shown in Figure 3. However, some of the farmers who are nonmembers of the cooperatives have already applied for membership in several cooperatives but are still on waiting list to become approved members. For instance, the number of farmers who had applied for the cooperative membership at Kassela is more than the current number of registered membership. This implies that the dairy cooperative movement in peri-urban system is growing at a very high rate due to the benefits associated it. These benefits include guaranteed market of milk to the farmers, extension services, trainings and provision of subsidized dairy inputs.

Among the all the information sharing pathways used by the cooperatives shown in Table 2, mobile phone was the most used pathway at $71.43 \%$. This is mostly through phone calls to the cooperatives by the dairy farmers and vice versa requesting different type's information available within the cooperative. Agricultural information is a key component in improving smallholder agricultural production and timely markets information, particularly of perishable items [11].

Mobile phone use was the most the common information sharing pathway along the peri-urban dairy sub-value with $93.4 \%$ at the farm level and $71.43 \%$ at the cooperative level are shown in Figure 4. Today in Africa most of the farmers do have mobile phone. Mobile phone is making the agricultural information more accessible and convenient to actors. However, the traditional approach of providing agricultural information through extension services is overstretched and under-resourced. Mobile has improved farmers' management of inputs and outputs supply by improving communication between farmers and traders also facilitate the provision of inputs to rural areas, by reducing their cost [12]. It has facilitated the delivery of other services such as money transfer (known as m-money), a system whereby money transferred to different users via a mobile phone [13]. It has increased accountability of extension service trough collecting data at farm and agent level. It has increased communication linkages with the research systems by improving communication flow between farmers, extension workers, research centers and vice versa [14]. Throughout the study, mobile phone use in information sharing by the peri-urban dairy farmers was the most common type of communication channel at $93.4 \%$ as shown in Figure 4. It has added a new dimension to communication between farmers which has enabled them to access extension services, help raise awareness, forecasts of weather conditions, milk prices, higher market participation by farmers and it can significantly reduce communication and information asymmetry that existed between the farmers and the traders [15]. Similar studies have shown that the use of phones among dairy farmers has linked them to market outlets and other service providers. These findings showed that farmers appreciated the use of mobile phone as easy, fast and convenient way to communicate [16]. It can also reduce the communication and information cost for rural communities and provides new opportunities for rural farmers to access to information on new agricultural technologies [17].

Mobile phone applications such as SMS, internet and voice can be used to collect data on farmers' adoption, yields and costs, rather than waiting for annual agricultural surveys [18] Text messaging or SMS is a feature of global System for Mobile (GSM) communication networks. Through SMS based support system farmers can receive automated price and weather information or request information on demand by texting keywords to an SMS server. The server can answered farmers through agricultural experts. However mobile phone has its limitations because the SMS carries only a limited amount of information and requires a basic level of education [19].

Flow diagram of information sharing strategies network and diffusion in Bamako peri-urban farming system is shown in Figure 5. The peri-urban dairy farmers, milk transporters 
and cooperatives are the key actors that form the social network in information dissemination and diffusion process. Among these key actors, mobile phone has been the most common type of information sharing pathway used along the dairy sub-value chain. According to [20] the exchange of information and its diffusion takes place within a social system. Actors such farmers, cooperatives, transporters and organization are the members of the social system. Therefore, it can be recommended as the most suitable communication intervention that can be used to reduce milk losses, increase productivity and incomes.

According to [21] any ICT intervention that improves the livelihoods of poor rural families will likely have significant direct and indirect impacts on enhancing agricultural production, marketing and post-harvest activities - which in turn can further contribute to poverty reduction. Mobile application development to connect all the actors with relevant the information sharing will help actors to reduce milk losses and increase productivity and income throughout the value chain. This mobile application will have an option of choosing local languages on its menu. This will allow farmers who do not have formal education but have received adult literacy education to relevant information on market price, milk quality, animal health and feeding. This new form of ICT will create a form of interaction between the dairy actors and the source of information at real-time basis. Whereas the traditional forms of information has been used in provision of advisory services but not on real-time basis. According to [22] radio and TV programs regularly feature weather and agricultural information in developing countries have provided information on price and quality. In some countries, national ministries of agriculture have attempted to integrate ICTs into information delivery services, specifically by establishing district information centers, with the growth of mobile phone coverage, many of these initiatives have moved away from "traditional" ICTs to mobile telephony, including voice, SMS, and internet-based services [23].

Information sharing through mobile phone is a system that can contribute towards reducing milk post-harvest losses along the value chain. Apart from the field days, workshops and media campaigns, mobile phone applications are increasingly effective medium for disseminating information aimed at directly minimizing or eliminating milk losses through information networks. The information network sharing will also act as a comprehensive and accurate electronic data and repository of dairy related statistics [24].

\section{Conclusion}

Milk losses along the peri-urban value chain are due to spoilage at the farm and cooperative level. This is an indicator that the actors lack information on dairy production and processing especially handling. The information sharing strategies along dairy value chain is mainly electronic media especially the mobile phone. The most sought types information by dairy actors are feeds and health services. The main sources of the information are the cooperatives.

\section{Acknowledgements}

This material is based upon work supported by the United States Agency for International Development, as part of the Feed the future initiative, under the CGIAR fund, award number BFS-G-11-00002, and the predecessor fund the Food Security and crisis mitigation II grant, award number EEMG_00-04-00013.

\section{Conflict of Interest}

The author declares that there is no conflict of interest regarding the publication of this paper.

\section{References}

[1] DNPIA Direction National des Productions and des Industries animales (2010). Rapport Annual.

[2] Konate, Y, Broutin. C, Dudez. P, Riber. D (2001). Préparation du voyage d"études pour des petites unités de transformation du lait en Afrique - financement CTA.

[3] DNPIA Direction National des Productions and des Industries animales(2015). Rapport Annual.

[4] USAID/EAT, ( 2012). LIVESTOCK IN MALIThe Business Enabling Environment for Livestock. This report is based on findings from the VcCLIR Mali diagnostic published in March 2012, funded by USAID/Mali, and was produced by USAID's Enabling Agricultural Trade (EAT) Project, and implemented by Fintrac Inc.

[5] Société des Laiteries du Mali SOLAIMA. (2014). Etude de relance des activités de la Sociétédes Laiteries du Mali.

[6] Mabe, L. K. and Oladele, O. I. (2016). Application of Information Communication Technologies for Agricultural Development through Extension Services: A Review. Information Technology Integration for Socio-Economic Development, 52.

[7] Ali J. and Kumar S. (2011). Information and communication technologies (ICTs) and farmers' decision-making across the agricultural supply chain. International Journal of Information Management, 149-159.

[8] World Bank (2011). Agriculture for Development', World Development Report, 200[86].

[9] Alemna A. A and Sam J. (2006). Critical Issues in Information and Technologies for Rural Development in Ghana. Information Development, 36-241.

[10] Yonazi, E Kelly, T Halewood, N and Colin Blackman, C (2012). "eTransform Africa: The Transformational Use of ICTs in Africa." Funding for the publication came from the AfDB Korean Trust Fund, the WB Pfizer Trust Fund and the WB Africa regional department.

[11] Rashid, A. T., \& Elder, L. (2009). Mobile phones and development: An analysis of IDRC-supported projects. The Electronic Journal of Information Systems in Developing Countries, 36

[12] Suri. T. F. (2011). "Selection and Comparative Advantage in Technology Adoption.” Econometrica, 79(1): 159-209. 
[13] Foster, A., Rosenzweig, M., 2010. Microeconomics of technology adoption. Annu. Rev. Econ. 2, 395-424.

[14] Dillon. B (2011). Using Mobile phone to collect panel data in developing countries. Journal of international development, volume 24 , issue 4 , pages $518-527$.

[15] Mugwisi T, Mostert J. and . Ocholla D. N (2014). Access to and Utilization of Information and Communication Technologies by Agricultural Researchers and Extension Workers in Zimbabwe. pages 67-84.

[16] Masuki, K. F., Tukahirwa J., Kamugisha R., Mowo J., Tanui J., Mogoi J. and Adera, E. O. (2009). Mobile phones in agricultural information delivery for rural development in Eastern Africa: Lessons from Western Uganda.

[17] Aker J. C. and Mbiti. I. (2010). Mobile Phones and Economic Development in Africa. Journal of Economic Perspectives, 207-232.

[18] Duflo. E, Rema. H and Stephen. R. (2007). "Monitoring Works: Getting Teachers to Come to School." BREAD Working Paper No. 103.
[19] Gakuru. M, Kristen. W and Francois. S. (2009). "Inventory of Innovative Farmer Advisory Services using ICTs." Prepared for The Forum for Agricultural Research in Africa.

[20] Rogers E. M (1995) Elements of Diffusion in innovations. New York: The Free Press.

[21] Richardson, D. (2005). How can agricultural extension best harness ICTs to improve rural livelihoods in developing countries. ICT in agriculture: Perspectives of technological innova.

[22] Goyal A. (2010). Information, direct access to farmers, and rural market performance in central India. American Economic Journal: Applied Economics 22-45.

[23] FARA Forum for Agricultural Research in Africa (2009). Inventory of innovative farmer advisory services using ICTs.

[24] Lore, T, Omore, A and Staal, S. 2005. Types, levels and causes of post-harvest milk and dairy losses in sub-Saharan Africa and the Near East: Phase two synthesis report. Nairobi, Kenya: ILRI. 